\title{
Health care in the caves
}

$\mathrm{P}$ roviding health care to indigenous peoples in remote areas is tricky at the best of times. Imagine, though, situations in which some of the patients are living in caves and the primary means of transportation for patients is riding a water buffalo.

Those are among the challenges faced by physicians seeking to provide care to members of the seven tribes the Cuyunin, Cagayanen, Agutaynin, Molbog, Tagbanua, Pala'wans and Batak - abiding on Palawan Island in the Philippines.

The caseload can be extremely challenging, from unusual fungal infections to untreated limb deformities caused by falls from coconut trees. And given the political realities of the Philippines, where it's not entirely uncommon for health care professionals, or for that matter, tourists to be ambushed or kidnapped, it's definitely disconcerting to be placed in the situation of delivering health care while completely surrounded by soldiers armed with grenade launchers.

Among other challenges?

Cultural beliefs and an almost pathological shortage of health care professionals and financial resources.

In short, "there is limited care and limited access to the limited care available," says Dr. Andrew Wilner, medical director of Lingkod Timog, a nonprofit organization based in Rhode Island that organizes annual medical missions to deprived areas of the Philippines.

Cultural obstacles are often an enormous barrier, says Dr. Beth Acala, chief of the community outreach division of the Provincial Health Office of Palawan. "They have cultural habits and behaviours that are not health promoting. For example, they prefer to give birth at home assisted by a family member, who is not trained. They also don't like vaccines or to go to midwives. They believe vaccines will kill the fetus."

"We will not change them," she adds. "We need to teach them to adapt

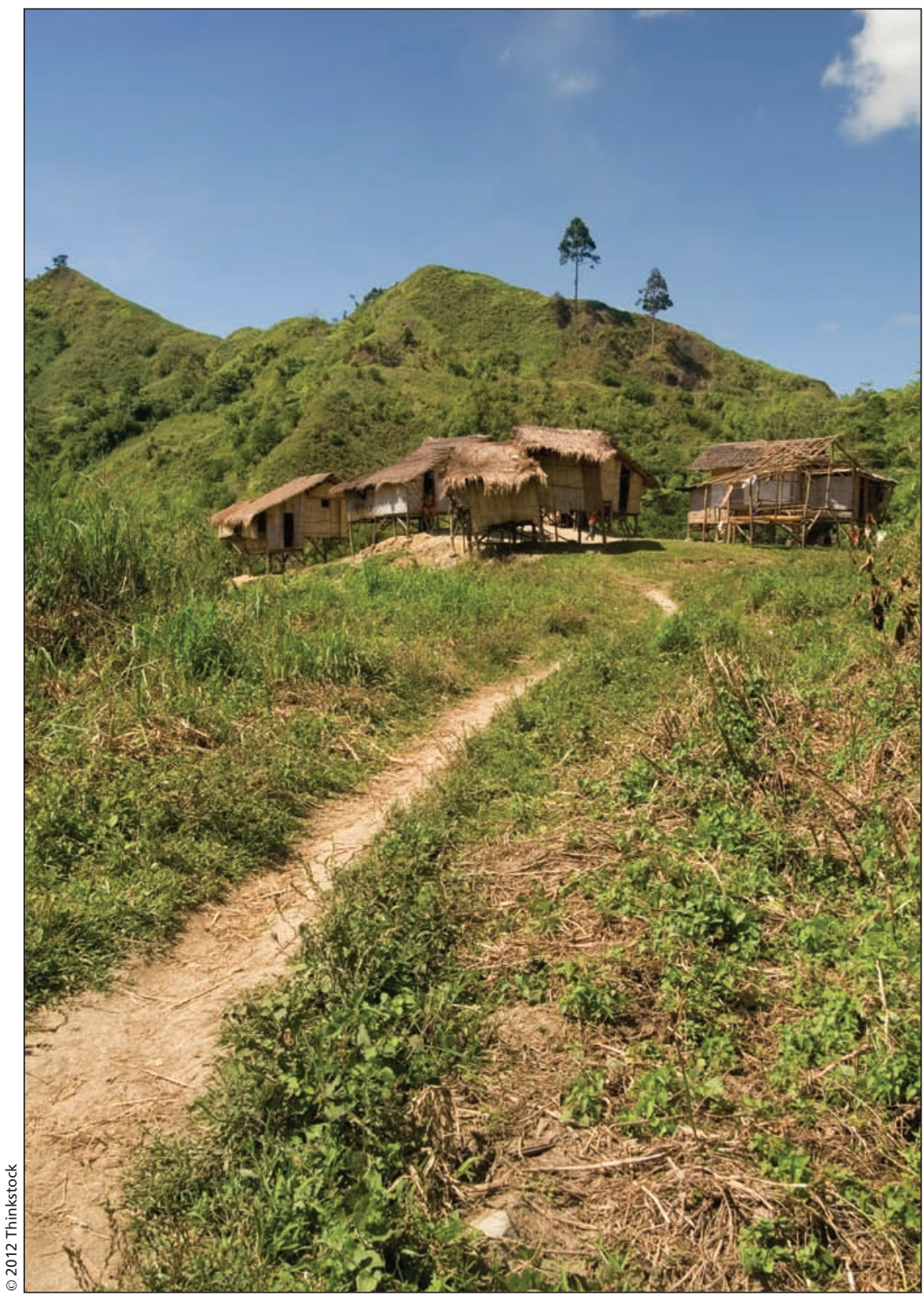

Remoteness, cultural beliefs, a shortage of financial resources and an almost pathological shortage of health care professionals are among challenges to providing health care in the Philippines.

so that it is possible to change behaviours that are not beneficial for health while retaining cultural behaviours."

Some physicians estimate that as many as $25 \%$ of the island's roughly 682000 inhabitants are indigenous peoples, often eking out a subsistence exis- tence by hunting, fishing and growing vegetables on small plots of mountainous land, and sometimes living in caves. There are 4241 households, with an average of five members per household, registered with NATRIPAL, says Gani Santos, research and documentation 
coordinator for the federation of indigenous peoples on the island.

The scale of unmet health needs is considerable, says Wilner. "Primary considerations for the indigenous people include the problems of hygiene, dental care, proper use of water, handwashing, toilet and sanitation."

Malnutrition is also a major problem in remote communities, adds Cecilia Sabban Marfil, a registered nurse based in Manila and a volunteer for Lingkod Timog. "These communities only have access to certain types of foods that they can grow like sweet potato, in root crops in mountains, and thus lack access to sources of proteins and vitamins."

Many health problems are a function of the fact that many indigenous peoples "are not aware of sanitary hygiene," says Santos. There's been a recent outbreak of cholera, while roughly 900 cases of dengue fever were reported in the Palawan region during the first nine months of 2011. Moreover, fungal skin infections, known locally as "buni," are highly prevalent and the likely product of river and creek bathing, he adds. And despite the availability of vaccines,
Marfil says poliomyelitis remains a problem.

Santos also notes malaria is a problem as many indigenous peoples can't afford mosquito nets. They often attribute mosquito bites to "evil spirits' anger," he says.

Beyond that lies the difficulty in finding physicians and other health care workers who are willing to venture into the tropical jungles.

"Most Filipino doctors prefer to work in the city," notes Dr. Lazir Penit, municipal health officer for the Rizal municipality in southern Palawan, who's responsible for providing health care to about 35500 people.

It's often left to military health care workers to make up the shortfall. "Doctors will only face frustration, as there is no upward career progression and they will not grow financially in remote areas where indigenous populations live. We are filling the gaps. We have a big role, as we're helping them in a way that nobody sees," says Lieutenant Donabelle Mapagu, staff nurse for the Western Command of the Armed Forces of the Philippines.
Structural reforms are needed, Wilner argues. "Nongovernmental organizations are insufficient. They're a drop in the bucket. For their lifelong health needs, these people need a refinement of the government health insurance plan." Those refinements, he argues, should include an improved vaccination program, as well as a significant expansion of hospitals, clinics and other facilities so that they're able to offer improved care. "Many people don't get simple services such as cataract surgery or cleft palate surgery because they can't afford it and the government doesn't provide it."

There's also a desperate need for more family planning, Wilner adds. "The other primary consideration for the indigenous people, as evidenced by one patient, when asked how many children she had, she responded with a question: alive or dead? Family planning and birth control services should be the foremost priority in terms of delivery of health care services." - Tiago Villanueva Gutierrez Arruda Marques MD, Puerto Princesa, Philippines

CMAJ 2012. DOI:10.1503/cmaj.109-4159 